\title{
TERRITÓRIOS, RIZOMAS E O CURRICULO NA ESCOLA
}

\author{
Franisco PerpetuoSantosDiniz \\ AnaCristina Lima da Costa* \\ RaimudbE nundmoSantosDiniz ${ }^{\text {twa }}$
}

Resumo: 0 presente artigo discute a possibilidade de pensar o currículo da escola formal na perspectiva da formação de um território-rizoma, ou seja, de uma proposta de estudo flexível, não hierárquica, interdisciplinar e baseada numa prática educativa voltada para o enfrentamento do modelo de educação disciplinar dominante. Primeiramente, são apresentados os conceitos de território e rizoma, segundo D eleuzee Guattari, para dar fundamento à noção de território-currículo no contexto da Ciência da E ducação. E m seguida, discute-se o currículo como a possibilidade de uma integração de saberes, conhecimentos, práticas educativas a serem desenvolvidas na escola formal e direcionadas à cidadania, à consciência política e à transformação social. Enfim, a análise feita entende o currículo num contexto holístico, crítico, flexível, rizomático, interdisciplinar e aberto a possibilidades de um novo fazer educacional.

Palavras-chave: Território. Rizoma. Currículo.

\section{TERRITORIE S, RHIZOMESAND THE SCH OOL CURRICULUM}

Abstract: This article discusses the possibility of thinking the formal school's curriculum from the perspective of formation of a rhizome-territory, that is, a flexible study proposal, non-hierarquical, interdisciplinary, and based on educational practices oriented as to confront the dominant disciplinary education model. Firstly, Deleuze and Guattari's concepts of territory and rhizome are presented in order to set basis for the notion of territory and curriculum within the context of the Sciences

\footnotetext{
${ }^{*}$ Especialista em Geografia da Amazônia (Faculdades Integradas Brasil Amazônia - FIBRA). Mestrando em Educação (Universidade do Estado do Pará). Professor da Secretaria Estadual de Educação (SEDUC-PA) e da Secretaria Municipal de Educação de Ananindeua (SEMED).

** Especialista em Fisioterapia Pneumofuncional e Fisioterapia nas Disfunções Traumato-Ortopédicas. Mestranda do Programa de Pós-Graduação em Educação (Universidade do Estado do Pará - UEPA). Docente da Universidade do Estado do Pará.

${ }^{* * *}$ Mestre em Planejamento do Desenvolvimento em Trópico Úmido (Universidade Federal do Pará: Núcleo de Altos Estudos Amazônicos - NAEA/UFPA). Professor da Secretaria Estadual de Educação (SEDUC-PA) e da Secretaria Municipal de Educação de Ananindeua (SEMED). Professor das Faculdades Integradas Brasil Amazônia (FIBRA).
} 
of Education. Next, the curriculum is discussed as possibility for the integration of knownledges, experiences, educational practices to be developed in formal schooling regarding citizenship, political awareness, and social transformation. Finally, the analysis considers the curriculum in a holistic context, critical, flexible, rhizomatic, interdisciplinary, opened to the possibilities of new educational doings.

Keywords: Territory. Rhizome. Curriculum.

\section{IN'TRODUÇÃO}

O território é unna categoria de análise que pode ser utilizada para a discussão da dimensão curricular da realidade educacional brasileira, numa perspectiva transformadora e comprometida com a superação do modelo de educação dominante que ignora saberes, conhecimentos, e favorece a especialização das disciplinas ratificando a prática do ensino e a aprendizagem sem relação entre os vários ramos do saber e contextos locais dos educandos.

O conceito de território é bastante discutido, na Ciência Geográfica e nas Ciências Naturais. O conceito de território se relaciona ao uso do poder, à dominação, à apropriação do espaço físico e às relações estabelecidas entre os homens e a natureza, os animais e o meio circundante. Contudo, outras Ciências Sociais e Humanas vêm rediscutindo esse conceito, a exemplo da Filosofia, da Sociologia e da Psicologia. O sentido dado ao território envolve a apropriação na perspectiva subjetiva, afetiva, sentimental, ontológica, entre outros. A discussão do conceito de território, nas Cièncias da Educação, está muito marcada pelas relações que envolvem o homem do campo e os processos educativos em ambientes formais escolares e não formais. Aqui, o território se insere como um eixo de debate da Ciência da Educação e é entendido como possibilidade de discussões sobre o currículo, o ensino e a aprendizagem.

A noção de território advogada no presente trabalho se fundamenta nos pressupostos teóricos de Gilles Deleuze e Félix Guattari, defendidos na obra O Que é Filosofía? (1992) e nos cinco volumes de Mil Platôs Na primeira obra, os autores afirmam que o conceito não é algo nunca visto antes, mas é resultado da formação de conceitos anteriormente definidos. A mesma regra serve para a noção de território como princípio básico uma nova territorialização ante um território anteriormente existente. Já em Mil patôs(1995), o território possui como estrutura basilar o constante porvir, a relação com a terra e a construção de processos de desterritorialização.

\section{4}

Ver a E ducação, v. 12, n. 2, p. 313-328, jul./ dez. 2011 
Deleuze e Guattari $(2005$, v.3) afirmam que são quatro os fatores que determinam a formação de territórios: os agenciamentos coletivos de corpos, os agenciamentos maquínicos de enunciação ${ }^{1}$, a desterritorialização e a reterritorialização. Os agenciamentos maquínicos de corpos e os agenciamentos coletivos de enunciação não são contraditórios como numa relação binária, não se opõem, nem se hierarquizam como o modelo árvore raiz. Desenvolvem-se concomitantemente. 0 movimento de desterritorialização tem a ver com 0 abandono de territórios. E a territorialização é o processo pelo qual se constrói o território. A desterritorialização não ocorre sem a reterritorialização - são inseparáveis e se completam, a exemplo da relação existente entre a orquídea e a vespa, destacadas por D eleuze e G uattari:

Como é possível que os modelos de desterritorialização e os processos de reterrito rialização não fossem relativos, não estivessem em perpétua ramificação, presos uns aos outros? $A$ orquídea se desterritorializa, formando uma imagem, um decalque da vespa; mas a vespa se reterritorializa, no entanto, tornando-se ela mesma uma peça no aparelho de reprodução da orquídea; mas ela reterritorializa a orquídea, transpondo o pólen. A vespa e a orquídea fazem rizoma em sua heterogeneidade. (DELEUZE; GUATTARI, 1995, v.3, p. 18).

A desterritorialização nunca ocorre isoladamente e é sempre resultado de um processo coletivo. Desterritorializar-se não significa a volta a uma territorialização anterior, como se fosse uma volta a um estado anteriormente existente. A desterritorialização se desenvolve com o processo de territorialização. Vejamos o que dizem Deleuze e Guattari sobre esse processo:

E la implica necessariamente um conjunto de artifícios pelos quais um elemento, ele mesmo desterritorializado, serve de territorialidade nova ao outro que também perdeu a sua. Daí todo um sistema de reterritorializações horizontais e complementares, entre a mão e a ferramenta. (DELEUZE; GUATTARI, 1995, v.3, p. 41).

A desterritorialização, para Deleuze e Guattari, é de dois tipos: a desterritorialização relativa e a desterritorialização absoluta. A primeira refere-se ao sócius, em que as sociedades abandonam os territórios que, concomitantemente, são reterritorializados. Criamos e recriamos territórios constantemente. Os 
autores argumentam que o Estado e o capitalismo são produtos do processo de desterritorialização e sobrecodificação. Por outro lado, as sociedades pré-capitalistas são eminentemente territoriais, na medida em que sua relação com a terra é oposta à gerada pelas ações do Estado e do capital, pois desenvolvem uma relação com a terra que supera o simples domínio de uma propriedade. A terra é a extensão da identidade, da subjetividade e da cultura. Apesar de o Estado, historicamente, desterritorializar as populações pré-capitalistas, elas criam estratégias de enfrentamento desse processo, com o devir de novas territorializações em face das desterritorializações que sofrem. Portanto, a desterritorialização relativa envolve a criação de territórios num constante porvir criando rotas de fuga e unindo-se a outras multiplicidades, dispostas a se relacionarem com outros filamentos que não param de modificar-se e unir-se. Ressalta-se que a desterritorialização absoluta refere-se a um estado de qualidade em relação à desterritorialização relativa e opera no plano do pensamento, no plano das ideias. A todo o momento, estamos criando novas ideias, consequentemente, estamos abandonando antigos territórios, estamos nos desterritorializando.

Ao analisarem o processo de desterritorialização que os nômades sofriam em decorrência da territorialização do Estado, Deleuze e Guattari (1995, v.3) evidenciaram, de forma muito clara, a dinâmica de criação e abandono de territórios. Fica claro que os nômades, pelo constante movimento de deslocamento e fluidez que realizam nos espaços que habitam, se caracterizam pela edificação de espaços lisos. O nômade representa a essência da territorialização imposta pelo Estado, na medida em que as terras anteriormente pertencentes a seu grupo passam a ter valor no mercado, sofrem uma dinâmica de codificação e controle. Mas o nômade, em decorrência da desterritorialização que sofre, abre um porvir na relação com o Estado. A terra, para o nômade, não tem valor-mercadoria, é o sáius coletivo. 0 sóusconfigura o espaço liso, o mais apto à realização do movimento de territorialização e desterritorialização:

Para o nômade, ao contrário, é a desterritorialização que constitui sua relação com a terra, por isso ele se reterritorializa na própria desterritorialização. É a terra que se desterritorializa ela mesma, de modo que o nômade aí encontra um território. A terra deixa de ser terra, e tende a tornar-se simples solo ou suporte. (GUATTARI; ROLNYK, 2010, p. 53).

Mesmo com a desterritorialização do nômade, sabemos que toda relação social tem por base um meio físico, pois seria impossível concebermos as dinâmicas

316

Ver a E ducação, v. 12, n. 2, p. 313-328, jul./ dez. 2011 
econômicas, políticas, ideológicas, religiosas, enfim, os processos sociais sem uma base territorial. Toda relação humana está situada num contexto espacial, caso contrário estariamos levitando ou flutuando e ela estaria se desenvolvendo no vácuo.

Em uma mesma base física, são produzidos inúmeros territórios que variam em perspectiva econômica, cultural, política, afetiva, subjetiva etc. A produção de territórios por uma população, povoados ou grupo de pessoas pode ser entendida como ações e projeções que buscam legitimar o controle de um conjunto de lugares, processos e ideias com delineamentos bem definidos. O território possui uma essência funcional que é expressa pelos seus múltiplos usos. O homem está em constante interação com o espaço físico onde vive e reproduz a base material e simbólico-subjetiva de sua existência. A ideia de território dada por Deleuze e G uattari apresenta as seguintes propriedades:

A noção de território é entendida aqui num sentido muito amplo, que ultrapassa o uso que dela fazem a etologia e a etnologia. Os seres existentes se organizam segundo territórios que os delimitam e os articulam aos outros existentes e aos fluxos cósmicos. O território pode ser relativo tanto a um espaço vivido, quanto a um sistema percebido no seio do qual um sujeito se sente "em casa". O território é sinônimo de apropriação, de subjetivação fechada sobre si mesma. Ele é o conjunto dos projetos e das representações nos quais vai desembocar, pragmaticamente, toda uma série de comportamentos, de investimentos, nos tempos e nos espaços sociais, culturais, estéticos, cognitivos. (GLATTARI; ROLNYK, 2010, p. 388).

A formação de territórios, para Deleuze e Guattari (1995, v.1), compreende a existência de processos que se articulam, se transformam, se renovam. Não existe um centro gerador de territórios. O território é originado a partir de diversas vertentes: subjetivas, políticas, econômicas, espaciais, entre outras. Nesse sentido, a existência de um território implica conexão com outros territórios, é o que dá origem a novas territorializações que se edificam e se desfazem num constante porvir, numa dinâmica de construção e integração, feito 0 crescimento de raízes que nunca param de crescer e se reproduzir.

Deleuze e Guattari $(1995$, v.1) flexibilizam o conceito de território, não definindo regras de análise, mas compreendendo-o como possibilidade de um movimento que se renova, se articula, se desfaz. O território é a expressão de um conjunto de processos que se integram. É a cartografia antecipada e discutida numa outra vertente; é o rizoma que se anuncia, sem alarde, sem reforço ao corte, é mais 
uma haste que se abre ao novo, fazendo e desfazendo processos inconclusos e heterogêneos, feito ráizes que crescem e se propagam. O conceito e o território são raízes metafóricas que incentivam discussões e reflexões. Não importa a definição, mas a possibilidade constante de redefinir o definido.

Um conjunto de raízes em sentido figurado compreende vários territórios. Um território integra-se a outro, estando apto a entrelaçar-se e modificar-se. $O$ território, a exemplo dos rizomas, é o devir-raízes, maleável, sua natureza-terraraizes inspirando expansão e inconclusão.

Deleuze e Guattari $(1995$, v.1) especificaram os princípios da formação do rizoma, cujo conceito é originário da Biologia. O termo rizoma foi sistematizado na Botânica, sendo caracterizado pela união de raízes que não param de se reproduzir, sendo muito difícil identificar seu início e suas direções. O crescimento constante das rázes resulta na formação de um conjunto de teias complexas de rázes, a exemplo das gramíneas. Contudo, a perspectiva rizomática dada pelos autores supera a ideia do rizoma enquanto processo natural e adquire uma perspectiva ontológico-filosófica:

O rizoma conecta um ponto qualquer com outro ponto qualquer e cada um de seus traços não remete necessariamente a traços de mesma natureza; ele põe o jogo o regime de signos muitos diferentes, inclusive estados de não signos; o rizoma não se deixa reconduzir nem ao uno nem ao múltiplo. Ele não é o uno que se torna dois, nem mesmo que se tornaria diretamente três, quatro ou cinco etc. Ele não é múltiplo que deriva do uno... Ele não tem começo nem fim, mas sempre um meio pelo qual ele cresce e transborda. (DELEUZE; GUATTARI, 1995, v. 1, p. 32).

É nitida, nessa primeira definição de rizoma, a ideia de processualidade, fato que marca a cartografia definida pelos autores. É importante ressaltar que o rizoma não apresenta modelos definidos a serem copiados e reproduzidos. Pelo contrário, o rizoma é marcado pela transformação constante que, ao modificar-se, acaba negando sua origem, não no sentido de simples oposição, mas de mudar sua natureza gerativa, mesmo que apresente marcas de sua gênese de formação.

Deleuze e Guattari $(1995$, v.1) especificaram os seis fundamentos do rizoma: a conexão, a heterogeneidade, a multiplicidade, a ruptura a-significante, a cartografia e o decalque.

O primeiro fundamento do rizoma é o da conexão. Da mesma forma que ocorre a interseção das raízes de determinadas plantas, como as gramíneas, que 
ao se unirem dão origem a novas ráżes, o rizoma, na perspectiva ontológica, está num constante movimento de expansão ou territorialização-desterritorialização ${ }^{2}$. A cada vez que ocorre a expansão das hastes, filamentos ou linhas de fuga do rizoma, são formadas novas conexões:

Qualquer ponto de um rizoma pode ser conectado a qualquer outro ponto e deve sê-lo. É muito diferente da árvore ou da raiz que fixam um ponto, uma ordem... Num rizoma, ao contrário, cada traço não remete necessariamente a um traço lingüístico: cadeias semióticas de toda a natureza são ai conectadas a modos de codificação muito diversos. (DELELZE; GUATTARI, 1995, v.1, p. 15).

O segundo princípio do rizoma é a heterogeneidade, caracterizada pela conexão gerada que impulsiona a formação de novos grupos de hastes os quais apresentam, em sua essência, a diversidade. A cada linhagem que se conecta, surgem novas cadeias ou territórios diferentes dos anteriores e aptos a se integrarem a outras linhagens. As linhagens são formadas sem hierarquias. Deleuze e Guattari criticam a Teoria Linguística de Chomski pelo constante retorno a um ponto principal, a língua matriz, a reflexão da sociedade, da política e da economia, feita a partir da supervalorização da gramática normativa:

$A$ árvore lingǘstica à maneira de Chomski começa ainda num ponto S e procede por dicotomia... Na lingǘstica, mesmo quando pretende-se ater-se ao explicito e nada supor da língua, acaba-se permanecendo no interior das esferas de um discurso que implica ainda modos de agenciamento e tipos de poder sociais particulares. (DELEUZE; GLATTARI, 1995, v.1, p. 15).

A multiplicidade é o terceiro princípio do rizoma e é gerada a partir da mudança natural do rizoma. O rizoma tanto pode crescer quanto pode parar de crescer quando, em determinados momentos, setores ou áreas congelam-se e, novamente, voltam a crescer, surge a multiplicidade. Quando o rizoma se expande através de suas "raizes", processo inerente à sua natureza, a multiplicidade se afirma. A multiplicidade é o rizoma que se expande e que muda sua origem.

O quarto princípio do rizoma é o da ruptura a-significante que se constitui nos cortes feitos no rizoma. O mais importante não é a ênfase ao corte, mas a possibilidade de regeneração e proliferação do rizoma. Quando se dá demasiado valor ao corte, corre-se o risco de congelar o processo de expansão do rizoma. 
A ruptura a-significante implica não caricaturizar a imagem do corte ou enfatizar um mapa recortado:

Seguir sempre o rizoma por ruptura, alongar, prolongar, revezar a linha de fuga, fazê-la variar, até produzir a linha mais abstrata e a mais tortuosa, com n dimensões com direçôes rompidas. Conjugar os fluxos desterritorializados. Seguir as plantas: começando por fixar os limites de uma primeira linha segundo círculos de convergência ao redor de singularidades sucessivas; depois, observando-se, no interior desta linha, novos círculos de convergência se estabelecem com novos pontos situados fora dos limites e outras dimensões. ((DELELZE; GUATTARI, 1995, v.1, p. 20).

A ruptura a-significante expressa o processo pelo qual ocorre o abandono do território com o desenvolvimento de uma nova reterritorialização. Uma depende da outra, numa relação que demonstra interdependência.

O quinto princípio do rizoma é a cartografia, identificada como o acompanhamento do processo de formação de mapas, territórios, territorializações e desterritorializações. Um mapa é formado com o processo de desenvolvimento do rizoma.

Quando o mapa deixa de ser rizomático e passa a ser decalcado, torna-se um modelo árvore raiz que se constitui no sexto princípio do rizoma. O decalque é a imagem congelada do mapa. Um rizoma, quando não se expande, torna-se a imagem do decalque do mapa. Não há mapa sem processo, sem linhas de fuga que crescem e se rompem, formando territorializações e desterritorializações:

O mapa é aberto, é conectável em todas as suas direções, desmontável, reversivel, suscetível de receber modificações constantemente. E le pode ser rasgado, revertido, adaptarse a montagens de qualquer natureza, ser preparado por um indivíduo, um grupo, uma formação social. Pode-se desenhá-lo numa parede, concebê-lo como obra de arte, construído como uma ação política ou como uma meditação. (DELELZE; GUATTARI, 1995, v.1, p. 22).

O mapa não apresenta cadeia genealógica definida, não possui tronco germinador, é o rizoma em si. "O rizoma se refere a um mapa que deve ser produzido, construído, sempre desmontável, conectável, reversível, modificável, com múltiplas entradas e saidas, com suas linhas de fuga". (DELEUZE; GUATTARI, 1995, v.1, p. 23). O decalque hierarquiza, impõe escalas de influência aos elementos constituintes

320

Ver a E ducação, v. 12, n. 2, p. 313-328, jul./ dez. 2011 
do modelo árvore-raiz. "Ele gerou, estabilizou, cristalizou o rizoma, e já não reproduz senão ele mesmo". (DELEUZE; GUATTARI, 1995, v.1, p.17). Entre ambos, não existe oposição. $O$ decalque pode ser formado a partir do rizoma e o rizoma pode romper-se do decalque e formar um mapa. Para Deleuze e Guattari o mapa é a expressão da multiplicidade do rizoma.

O rizoma, quando discutido para se analisar o currículo, a escola e a construção de práticas educativas, abre a possibilidade de novo pensar e novo fazer educacionais. O princípio da conexão do rizoma dá às disciplinas curriculares margem para se integrarem sem hierarquias. A heterogeneidade incentiva a superação de conteúdos já decalcados. A multiplicidade orienta a necessidade de se realizar, no currículo, metamorfoses, mudanças. A ruptura a-significante pretende "misturar-se" com o atual modelo de conhecimento, realizando transformações, sem valorizar os cortes. A cartografia representa os saberes formados no cotidiano escolar, e o decalque é o modelo de educação vigente erodido pela luta políticopedagógica que nunca se esgota. O currículo-rizoma é um mapa formado por territorializações criadas e recriadas, no interior da escola formal, e direcionado a uma identidade libertadora.

O currículo, quando pensado na perspectiva do rizoma, não apresenta começo nem fim. O currículo até pode apresentar decalque, porém deve ser constantemente repensado. O currículo-rizoma é múltiplo, diverso, adaptável, não nega sua origem, mas cria possibilidade de inovação, invenção e conexão.

Enfim, o curriculo-rizoma funde saberes: a ciência, a religião, a filosofia, o senso comum, as artes e o mito formam cosmos, teias que são tecidas como fios de crochê, sempre abertas a novos pontos, mas que almejam traçar várias direções e visam à construção de complexas redes de conhecimento, conectadas, sem vaidades, que dialogam entre si, se abrem e convidam à integração entre as disciplinas curriculares.

\section{O CURRÍCULO E A DIVERSIDADE DE SABERES NA ESCOLA}

O currículo oficial, definido pelo Ministério da Educação para ser seguido pelas escolas de todo o país, se caracteriza por fragmentação e especialização das disciplinas. Em decorrência da falta de políticas governamentais direcionadas ao trabalho com e ao ensino de conteúdos da Língua Portuguesa, Matemática, Geografia, História, Filosofia, Sociologia, Ciências Naturais, entre outras, cria-se um quadro de separação de conteúdos que, em geral, favorece a construção de planos de abstração, o que impede conjecturas a propósito da realidade sociopolítica e cultural dos alunos. A superespecialização das disciplinas curriculares é reflexo 
da hierarquização e da especialização dos ramos científicos impostos pelo modelo de ciência dominante.

O modelo de ciència dominante é ocidental, tem suas bases centradas no racionalismo aprimorado no século XVI. O conhecimento científico nega outras formas de conhecimento, não considera a subjetividade, o senso comum, a aprendizagem, a construção e a socialização de conhecimentos feitos a partir de vivências individuais e coletivas. Nesse contexto, a natureza é separada do homem e vista como uma grande engrenagem regida por leis invariáveis pertencentes a uma complexa máquina que deve ser domesticada, dominada. Para Deleuze e Guattari (1995, v.5), a ciência hegemônica é regia e apresenta leis imutáveis que buscam padronizar as realidades e fenômenos.

A análise dos fatos sociais, no modelo hegemônico de ciência, deve ser conduzida a partir de modelos advindos das ciências tidas como exatas e naturais. Já as Ciências Sociais nasceram embebidas com o positivismo. As leis que regiam a natureza deviam ser as mesmas que determinariam a sociedade. A sociedade deveria ser estudada de forma neutra, objetiva, sem juízos de valor, sem pré-noções ou conceitos, sem paixões, nem ideologias, nem crenças.

Para Santos (2010), o pensamento moderno é pós-abissal e não derivativo, envolve uma ruptura radical com as formas ocidentais modernas de pensamento e ação. Usando uma epistemologia do sul, confronta a monocultura da ciència moderna com uma ecologia de saberes. A ecologia de saberes baseia-se na ideia de que o conhecimento é interconhecimento e postula a noção da diversidade epistemológica do mundo - o reconhecimento da existência de uma plutalidade de formas de conhecimento, da impossibilidade de uma epistemologia geral. $O$ pensamento abissal consolidou a crença na ciência como única forma válida e rigorosa no que tange à produção do conhecimento.

Acompanhando a crítica ao rigor do modelo de ciência dominante e a falta de integração sobre as diversas expressões de conhecimentos, Morin (2004) aborda a necessidade de valorizar a complexidade do conhecimento rumo à ecologia de saberes, em que o pensamento complexo é tido como a aproximação, a relação, as misturas e integrações dos conhecimentos separados pelo próprio processo de desenvolvimento das ciências. O pensamento da complexidade valoriza a reciprocidade das partes, advoga que o local modifica o todo e o todo, o local; reconhece a diversidade na unidade e abre-se ao contexto planetário, não abre as fronteiras entre as disciplinas, mas transforma o que produz as fronteiras, o que organiza o conhecimento.

Da mesma forma que o conhecimento científico impõe um modelo a ser seguido, desconsiderando outras formas de conhecimento, o currículo da escola 
formal vem sendo historicamente ditado e estruturado numa separação explícita entre as ciências ditas curriculares e outras formas de saberes científicos e não científicos. Tal situação favorece a permanência de um modelo educacional segregador, que reforça as desigualdades sociais. $O$ conhecimento produzido a partir do currículo escolar é abstrato, especializado e enfadonho. Contudo, a complexidade do conhecimento impõe à escola a possibilidade de romper com as formas de ensino fragmentadas e sem conexões, ao mesmo tempo em que abre a possibilidade de se construir um território, no interior da escola, no próprio currículo oficial, para a reformulação da educação em base críticas e com funcionalidade social.

O modelo de ciência, de currículo e de escola dominantes vem sendo criticado por um conjunto de transformações advindas de vários campos científicos, políticos, culturais e sociais:

Essa crise é não só profunda como irreversível; julgo que estamos a viver um período de revolução científica que se iniciou com Einstein e a mecânica quântica e não se sabe ainda quando acabará; terceiro, que os sinais nos permitem tão só especular acerca do paradigma que emergirá deste periodo revolucionário, mas que, desde já, pode afirmar-se com segurança que colapsarão as distinções básicas em que assenta o paradigma dominante. (SANTOS, 2009, p. 68).

Para Santos (2009), o paradigma científico vem sendo abalado pela teoria da relatividade, pela fisica quântica, pela crítica ao rigor da matemática, pelos avanços da microfísica, da química e da biologia fundamentais na teoria dos sistemas o que favoreceria a imutabilidade da ciència moderna.

A ciência hegemônica e as formas de conhecimentos marginalizados, as concepções de mundo e os saberes dos educandos encontram-se num processo de territorialização e desterritorialização em decorrência das interseções e dependência entre ambas. São as zonas de fugas, as fronteiras que são construídas e movidas num constante movimento de ida, volta e transformação.

Deleuze e Guattari $(1995$, v.1) reconhecem a existência de uma fronteira aberta e em constante movimentação entre o modelo da ciência rígida e a ciência nômade ${ }^{3}$, aqui entendida como feita por todos os grupos de conhecimentos e saberes marginalizados pela ciência oficial:

Por isso, o mais importante talvez sejam os fenômenos fronteiriços onde a ciência nômade exerce uma pressão sobre a ciência do estado, e onde, inversamente, a ciência de Estado 
se apropria e transforma os dados da ciência nômade. Isso é verdade da arte dos campos e da costrametaçãa que sempre mobiliza as projeções e os planos inclinados: o Estado não se apropria dessa dimensão da máquina de guerra sem submetê-la a regras civis e métricas que vão limitá-las de modo estrito, controlar, localizar a ciência nômade, e proibi-la de desenvolver suas conseqüências através do campo social. (DELELZE; GUATTARI, 1995, v.5, p. 27).

Santos (2009) também reconhece a existência de fronteiras entre as ciências hegemônicas e as formas de conhecimentos e saberes marginalizados, que se interconectam à semelhança de rizomas:

Os fatos observados têm vindo a escapar ao regime de isolamento prisional a que a ciência os sujeita. Os objetos têm fronteiras cada vez menos definidas; São constituídos por anéis que se entrecruzam em teias complexas com os restantes dos objetos, a tal ponto que os objetos em si são menos reais que as relações entre eles. (SANTOS, 2009, p. 73).

Quando Santos (2009) afirma que o conhecimento é parcelado nas especializações da ciência, reportamos ao modelo árvore-raiz definidos por Deleuze e Guattari, na obra Mil Platôs (1995, v.1; v.3; v.5). A Ciência Moderna e o Currículo seriam a grande árvore do conhecimento, e seus galhos assemelham-se às especializações das disciplinas escolares. Esse modelo expressa o sexto princípio do rizoma, o decalque, caracterizado pela imagem estática de um modelo hegemônico de ciência e de currículo. Por outro lado, quando Santos afirma que os objetos possuem fronteiras definidas e que se intercruzam, formando teias complexas, relacionamos tal noção ao quarto princípio do rizoma, à ruptura a-significante, em que se desenvolveriam os processos de territorialização e desterritorialização. Por fim, as linhas de fuga comuns aos rizomas unir-se-iam a outras raízes formando novas teias complexas.

\section{TERRITÓRIOS, RIZOMAS, EDUCAÇ̃̃O E CURRÍCULO}

Os modelos científicos e curriculares hegemônicos determinaram a fragmentação e a especialização das Cièncias e das disciplinas curriculares e se constituíram numa grande árvore-decalque. Os galhos e follhas da árvore-mãe são todas as disciplinas - Física, Sociologia, Matemática, Geografia, Química, Filosofia, História, Letras, Artes, Biologia, entre outras que brotaram, no século XIX, de uma única matriz, o positivismo - e são afirmados na escola formal na atualidade.

\section{4}

Ver a E ducação, v. 12, n. 2, p. 313-328, jul./ dez. 2011 
Há predominância de um grande território da especialização e hierarquização do saber. A escola e o currículo são influenciados e determinados pelas territorializações do decalque científico dominante. Contudo, Deleuze e Guattari (1995, v.1; v.3), Santos (2009) e Morin (2004) discursaram sobre as fronteiras entre o saber científico, os saberes populares e todas as outras formas de expressão de saberes, e sobre todas as suas complexidades. Cabe ao Estado negar sua função, a escola; aos educadores e a todos os comprometidos com uma proposta educativa voltada para a consciência política e cidadania, revalorizar as fronteiras entre as ciências, buscar incessantemente as relações entre o saber científico e o senso comum, romper com as amarras dos conteúdos que são impostos de forma abstrata no interior das escolas.

A perspectiva de territórios e rizomas orienta uma nova proposta de educação. Deleuze e Guattari (1995), ao afirmarem que a territorialização implica desterritorialização, abrem um espaço para uma profunda reflexão sobre as relações possiveis entre a territorialização da ciência e o entendimento do saber numa perspectiva complexa, escolar e curricular. A fronteira que se forma entre a conexão de saberes é caracterizada pela interação de conhecimentos que abarcam multiculturalismo, Á frica, indígenas, religiosidade, sincretismo religioso, beberagem na Amazônia, cultura popular, meio ambiente, senso comum, saber científico, cidadania, direitos humanos, disciplinas curriculares, entre outros, todos, sem exceção, formando um rizoma ou um conjunto de rizomas, com fronteiras abertas à multiplicidade, a heterogeneidade, a constituição de mapas e territórios, a superação de decalques, a interdisciplinaridade, pertencentes a uma grande teia de conhecimentos, holisticamente aceita, sem hierarquizações e especializações. Cabe à escola compor uma haste de um rizoma maior, composto pelos movimentos sociais, igrejas, ONGs, universidades, intelectuais e movimentos organizados, e caminhar rumo à fronteira da liberdade objetivando romper o decalque social e científico que cristaliza a divisão de classes e a abstração de saberes. A escola, a educação e a luta política, vistas de forma integrada, se constituem em territórios-rizomas cuja territorializações desterritorializam a territorialização abissal da sociedade enrijecida em que vivemos.

Quando se questiona o rigor e a dureza do currículo escolar oficial e se abre a discussão para a inserção de novas práticas, teorias, saberes e conhecimentos sobre o local e o global, a ciência e o cotidiano, a dureza e a leveza das disciplinas curriculares, novas possibilidades de fazer educação são constituídas. 0 currículo visto na perspectiva rizomática não abandona as disciplinas oficiais - une-se a elas, mas abre-se ao novo, ao porvir ao processo educativo, ao novo território que desterritorializa a ciência de Estado e o currículo duro da escola oficial. 
A escola deve imitar o nômade e revalorizar a territorialidade do sóius, da vivência local, da identidade que é formada a partir do meio circundante. $O$ nômade cria e recria territórios. A escola deve criar e recriar currículos-territórios que possam ir na contramão da territorialidade imposta pelo Estado.

O território-currículo da escola deve ser flexível, conectado às transformações locais e globais da sociedade, considerar as multiplicidades de disciplinas e saberes, evitando, dessa forma, decalcar currículos que reproduzam o modelo árvore-raiz da educação. O currículo que se congela nega o processo, nega o porvir da cartografia deleuze-guattariana.

O currículo é o devir que se anuncia, é o mapa da educação que é formado e muda a partir de iniciativas coletivas que se rompem e se espalham polarizando novas práticas, novos caminhos. O currículo-território - ou currículo na perspectiva do rizoma - não estabelece hicrarquia entre as ciências e disciplinas curriculares, considera as expressões de saberes, não tem árvore genealógica nem caminhos previamente estabelecidos, não se configura na grande árvore de conhecimento, evita o modelo de decalque.

O território-currículo compreende a ruptura a-significante, expressa o abandono de territórios em decorrência de uma territorialização que se impõe composta por linhas de fuga, prontas a emergirem em mapas de um porvir. $O$ currículo inerte é o decalque em si, parou o rizoma. É o rizoma decalcado. O território-currículo comunga com a ecologia de saberes e vê a escola como raízes, rizomas, saberes e conhecimentos que se interceptam, que não se congelam, mudam, e que não param no tempo. Portanto, se a escola e o modelo de educação vigentes no Brasil não se modificarem, como acontece com os rizomas que estão em constantes transformações, estarão fadados ao fracasso e continuarão reproduzindo conhecimentos hierarquizados e desvinculados da sociedade. 


\section{NOTAS}

${ }^{1}$ Para Deleuze e Guattari $(1995$, v. 3) os agenciamentos de corpos são as relações expressas nas subjetividades criadoras de certas identidades fisicas e de dependência entre os sujeitos, a ex: das relações pai, mãe e filho; Professor-aluno, Chefeempregado. Já os agenciamentos coletivos de enunciação compreendem a formação da subjetividade que é exterior ao indivíduo, ou seja, os sistemas religiosos, econômicos, sociais, políticos, entre outros são responsáveis pela elaboração da personalidade das pessoas. A subjetividade não nasce de dentro do sujeito, mas vem de fora e é internalizada.

${ }^{2}$ O movimento de desterritorialização tem haver com o abandono de territórios e a territorialização é o processo pelo qual se constrói o território. A desterritorialização não ocorre sem a reterritorialização. Ambos são inseparáveis e se completam a exemplo da orquídea e da vespa. A desterritorialização nunca ocorre isoladamente e é sempre resultado de um processo coletivo.

${ }^{3}$ Para Deleuze e Guattari (1995, v. 5): as populações pré-capitalistas desenvolvem uma relação com a terra que supera o simples domínio de uma propriedade. A terra é a extensão da identidade, subjetividade e cultura. Apesar do Estado historicamente desterritorializar as populações pré-capitalistas, as mesmas criam estratégias de enfrentamento desse processo, com o devir de novas territorializações frente às desterritorializações que sofrem. Portanto, a desterritorialização relativa, envolve a criação de territórios num constante porvir, criar rotas de fugas e unire-se a outras multiplicidades, como num rizoma. A desterritorialização absoluta referese a um estado de qualidade em relação à desterritorialização relativa e opera no plano do pensamento, no plano das idéias. A todo o momento estamos criando novas idéias, consequientemente estamos abandonando antigos territórios, estamos nos desterritorializando. Porém, o pensamento só existe a partir do meio, a Terra.

\section{REFERÊNCIAS}

DELEUZE, Guilles; GUATTARI, Félix. O que é Filosofia? Rio de Janeiro: Ed. 34, 1992. (Coleção TRANS).

. Mil platôs: capitalismo e esquizofrenia. (5 v.). São Paulo: Ed. 34, 1995, v.1. . Mil platôs: capitalismo e esquizo frenia. (5 v.). São Paulo. Ed. 34, 1995, v.3. . Mil platôs: capitalismo e esquizofrenia. (5 v.). São Paulo. Ed. 34, 1995, v.5. GUATTARRI, Félix; ROLNYK, Suely. Micropolítica: cartografias do desejo. 10. ed. Petrópolis, RJ: Vozes, 2010. 
Francisco PerpetuoSantosDiniz / Ana Cristina Limada Costa/ RaimundoE nundnoSantosDiniz

MORIN, Edgar. A cabeça bem-feita: repensar a reforma, reformar o pensamento. 17. ed. Rio de Janeiro: Bertrand Brasil, 2004.

SANTOS, Boaventura de S. Da ciência moderna ao novo senso comum - A critica da razão indolente: contra o desperdício da experiência. 4. ed. São Paulo: Cortez. 2009.

Para além do pensamento abissal: das linhas globais a uma ecologia de saberes. In: SANTOS, Boaventura de S.; MENESES, Maria Paula. (Org:). Epistemologias do Sul. São Paulo: Cortez, 2010; p. 31- 83. 